\title{
BIO-GASEOUS FUELS FROM AGRICULTURAL WASTE PYROLYSIS (PART II)
}

\author{
Cora Bulmău ${ }^{1, *}$, Gabriela Ionescu ${ }^{1}$, and Cosmin Mărculescu ${ }^{1}$ \\ ${ }^{1}$ University Politehnica of Bucharest, Department of Energy Production and Use, \\ Splaiul Independenţei 313, Romania
}

\begin{abstract}
The results presented in the following paper are making the aim of a broadly research concentrated to investigate the temperature effects on agricultural waste pyrolysis performed in a batch reactor. Briefly, the motivation along with experimental features and main results generated from the rape straw low temperature pyrolysis $\left(300^{\circ} \mathrm{C}-500^{\circ} \mathrm{C}\right)$ have been offered in the first part submitted at the MSE 2019 conference, with the title: Bio-gaseous fuels from agricultural waste pyrolysis (Part I). The current section (second part of the study) presents the results obtained in case of the rape straw high temperature pyrolysis $\left(600^{\circ} \mathrm{C}-800^{\circ} \mathrm{C}\right)$. Overall, as expected, the augmentation of the operating temperature, inhibits the bio-oil and biochar formation, enhancing the pyrolysis gas production. The distribution of gaseous components varies depending on temperature and residence time. The transition stages and the formation of the main pyrolysis gaseous species are also presented and discussed. The most dominant chemical element from the pyrolysis gas is $\mathrm{N}_{2}$, due to its constant presence as non-oxidant agent in the process. Considering the same premise, the rape straw pyrolysis gaseous species distribution in the temperature range of $600^{\circ} \mathrm{C}-800^{\circ} \mathrm{C}$ varies between: $47 \%-58 \% \mathrm{CO}_{2}, 18 \%$ $28 \% \mathrm{CO}, 14 \%-35 \% \mathrm{H}_{2}$, while the pyrolysis gas density $1.1-1.4 \mathrm{~kg} / \mathrm{m}^{3}$ and higher heating value $23-52 \mathrm{MJ} / \mathrm{kg}$.
\end{abstract}

\section{Introduction}

Climate change, together with finding promising feedstock for alternative fuels and waste disposal, are one of the main global environmental issues, making renewable energy a topic of growing importance. The key factor in the Earth's changing climate is GHG (Greenhouse Gases) with high warming effect on environment. At global level, it is estimated that $25-28 \%$ of the GHG results from heat and electricity generation [ 1 - 3]. Biomass is one of the clean energy sources that contributes to the reduction of the GHG, supplementing the resources of fossil fuels in decline at the same time. Biomass for energy originates from a variety of sources resulted from forest, agriculture and waste [4 - 5]. At the EU level, in 2016, the gross final consumption of renewable energy in the heating and cooling (H\&C) market sector came from solid biomass $(83 \%$ of all Renewable Energy Sources - Heating \& Cooling: RES - H\&C), heat pumps $(10 \%$ of all RES - H\&C) and

* Corresponding author: cora4cora@gmail.com 
biogas (4\% of all RES - H\&C) [6]. Biomass can be treated in different technological ways to produce fuels. Two types of the methods usually adopted to generate fuels from biomass are: biological and thermal. Besides other thermal processes as combustion, gasification, liquefaction, pyrolysis is one of the mains. This consideration is since pyrolysis can be optimized to produce bio-gas, bio-oil or bio-char co-products, the process having a high potential for energy production, more than is invested [7 - 9]. It has been recognized its capacity to produce bio-fuels with high fuel-to-feed ratios [10] or to generate bio-char with many options for its use [11 - 13]. Therefore, in the past decades, pyrolysis has become an attractive way to convert biomass into bio-fuels.

Different types of pyrolysis processes and technological configurations can be used for bio-fuels production. Since the final temperature represents an important parameter, two main types of pyrolysis are used: "low-temperature" and "high-temperature". Low temperature pyrolysis $\left(300^{\circ} \mathrm{C}-500^{\circ} \mathrm{C}\right)$ can be considered as a rather low-tech and robust technology which has been optimized for biochar production. In the past, these processes had the most extensive application for charcoal production [14]. In some thermal process's designs, the liquid and gas products can escape as smoke leading to environmental pollution. High temperature pyrolysis converts biomass to products, usually in the range of $600^{\circ} \mathrm{C}-900^{\circ} \mathrm{C}$. To secure the instant conversion of the material, the feedstock must be dried to $<10 \mathrm{wt} \%$ water, and particles must be ground to $<2 \mathrm{~mm}$ to avoid important diffusion barriers and temperature gradients in the particles during the heating process $[15$, 16]. The humidity of the feedstocks used is another key parameter that helps to decide in choosing the pyrolysis processes. There is previously research developed that concluded a material with high water content is desirable for these thermochemical processes. Some authors put also in discussion the application of pyrolysis to woody agricultural biomass waste $[17,18]$ or municipal solid wastes [19].

Pyrolysis is an opportunity to convert biomass into more clean fuels (bio-fuels) instead of converting biomass directly into energy by traditional combustion, which is a more pollutant process for the environment. Agricultural wastes are currently seen as low-valued materials but are beginning to be recognized as resources to produce a variety of ecofriendly and sustainable products: bio-oil, bio-char and bio-gas [20-21].

In recent years the first two products already mentioned are the most attractive products of pyrolysis, but the process can be optimized to produce bio-gas because it can also be used as fuel, as it has a high calorific value.

Therefore, the present study deals to investigate the effect of the process temperature on the pyrolysis bio-gaseous product in order to optimize the process to produce gas with energy content higher than initial agriculture biomass. So, chemical compounds of pyrolysis gas relevant to fuel applications were assessed in case of rape straw fast pyrolysis processes. In this context, empirical approaches to evaluate the energy value and density of the bio-gaseous product of pyrolysis process were applied.

\section{Material and methods}

The data referring to the feedstock, its characteristics and experimental methods applied to the current research study have been already detailed in the first part of the manuscript. Therefore, here, only the obtained results will be presented and discussed. 


\section{Results and discussions}

Further in this section we will refer to the outcomes generated by the experiments concerning high temperature pyrolysis of the rape straw. These will be then compared with the results obtained from the low temperature pyrolysis applied to agriculture biomass residues.

The influence of different peaks of pyrolysis temperatures $\left(600^{\circ} \mathrm{C}, 700^{\circ} \mathrm{C}\right.$ and $\left.800^{\circ} \mathrm{C}\right)$ on the gas compounds released during thermochemical process developed in a batch tubular reactor was assessed. The experimental results of the research study revealed that the increase of temperature produces an augmentation of the pyrolysis gas fraction in case of the used agriculture residues. The chemical compounds analyzed in our study were: oxygen $\left(\mathrm{O}_{2}\right)$, carbon dioxide $\left(\mathrm{CO}_{2}\right)$, carbon monoxide $(\mathrm{CO})$ and hydrogen $\left(\mathrm{H}_{2}\right)$. These gas species can be products of the primary decomposition reactions formed by bond breaking of the main components of the lignocellulosic agriculture biomass: cellulose, hemicellulose or lignin, or those resulted from secondary cracking ones [22].
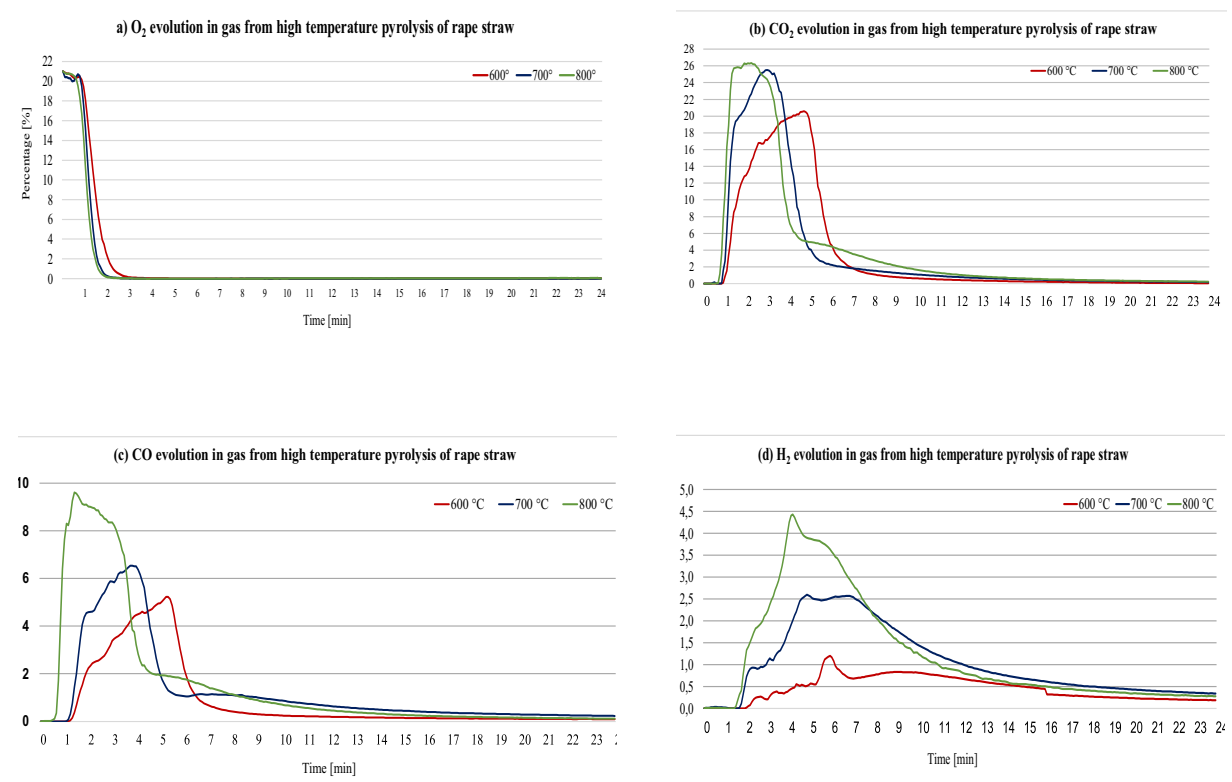

Fig. 1. Temperature effect on compounds of gas resulted from rape straw high temperature pyrolysis: (a) $\mathrm{O}_{2}$; (b) $\mathrm{CO}_{2}$; (c) $\mathrm{CO}$; (d) $\mathrm{H}_{2}$

The analyzer adopted for experiments doesn't allow to detect nitrogen $\left(\mathrm{N}_{2}\right)$ concentration, so the amount of this inert gas was determined by difference. Because $\mathrm{N}_{2}$ has the role to be the inert carrier gas for the process, this was constantly presented during the thermochemical degradation of the rape straw. Thus, $\mathrm{N}_{2}$ is the central chemical compound from the pyrolysis gas and its concentration was distributed among all the primary gas compounds analyzed for our study: $\mathrm{CO}_{2}, \mathrm{CO}$ and $\mathrm{H}_{2}$. In industrial application, the inert gas is not permanently present during the process, just for the start-up to remove the oxygen and overcome the possible thermal oxidation of the feedstock [23]. In case of the industrial pyrolysis systems, the $\mathrm{N}_{2}$ flow is very well controlled because of the dew point of the vapors condensation that strongly depends on the quantity of inert gas introduced in the process [24]. 
Figure 2 illustrates the variation of the concentration for the main gases evolved during high temperature pyrolysis of the biomass samples as a function of time. A high level of $\mathrm{O}_{2}$ concentration in pyrolysis gas happened in case of high temperature pyrolysis processes. The same trend was registered for low temperature pyrolysis of rape straw, and results for these were discussed in the first part of the paper. Therefore, this strengthens our explanation: the presence of $\mathrm{O}_{2}$ in pyrolysis gas is due to the rape straw residual chemical properties, the unoccupied volume of the feedstock in the crucible, and the reactor charged operation in the pre-heated refractory steel tube. The $\mathrm{O}_{2}$ proved a decrease trend of concentration while the pyrolysis process stages happened and this was totally consumed after approximately 2-3 minutes, a shorter time compared with that from the low temperature pyrolysis. The $\mathrm{CO}_{2}$ maintained the same decreasing tendency for high temperature processes as well as for pyrolysis developed at low temperatures. The CO concentration revealed different transition: it kept the trend to increase if the process temperature increases only for the first two temperatures: $600^{\circ} \mathrm{C}$ and $700^{\circ} \mathrm{C}$. The temperature of about $800^{\circ} \mathrm{C}$ assured during the process lead to a net reduction of $\mathrm{CO}$ content. When the peaks of temperatures increase, a clear rise of $\mathrm{H}_{2}$ concentration happened. So, generally, we can conclude that $\mathrm{CO}$ and $\mathrm{CO}_{2}$ are gas chemical compounds that are not favored by high values of the process temperatures, while for $\mathrm{H}_{2}$, high pyrolysis temperature lead to high production values [25].

Figure 3 illustrates the progress of the chemical primary components of the gas generated from the rape straw thermal degradation in case of low temperature pyrolysis, as well as for high temperature pyrolysis.

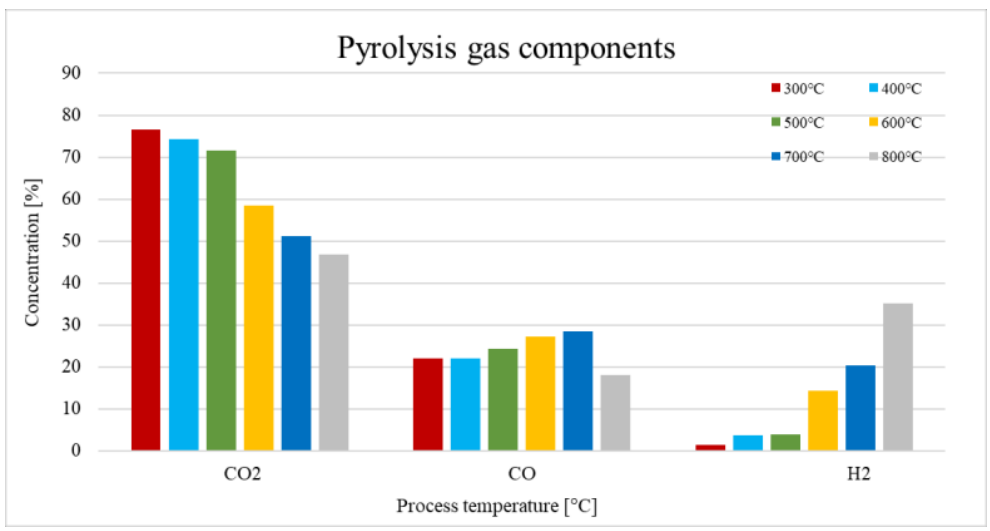

Fig. 2. Trend for concentration of gas compounds generated from rape straw pyrolysis

The results of the experimental study concerning the values of $\mathrm{CO}_{2} / \mathrm{CO} / \mathrm{H}_{2}$ concentrations from the pyrolysis of rape straw exposed the next distribution: 58 / $51 / 47$ $\left(600^{\circ} \mathrm{C}\right), 27 / 28 / 18\left(700^{\circ} \mathrm{C}\right)$ and $14 / 20 / 35\left(800^{\circ} \mathrm{C}\right)$. The big content of the $\mathrm{H}_{2}$ detected in the pyrolysis gas in case of high temperature is sustained also by other studies [26].

One of the main goals of the pyrolysis experiments was to obtain gas products with good density and energy potential (High Heating Value - HHV). Both gas properties depend by the process temperature and feedstocks, respectively. Empirical equations, based on participation of the chemical compounds and their properties, were used to determine the pyrolysis gas density and HHV. Considering the compounds analyzed in the study, the influence of pyrolysis on density and HHV of the produced gas are illustrated and discussed below. 


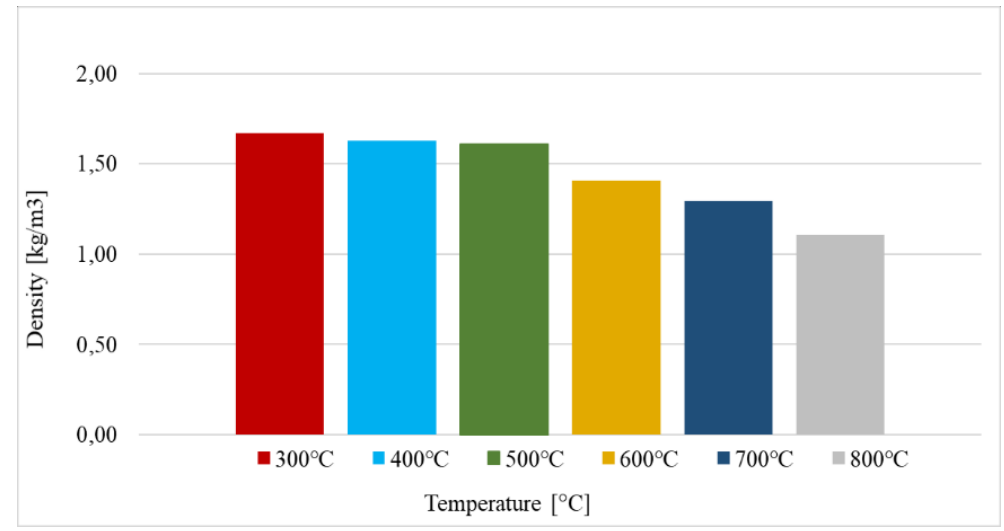

Fig. 3. Density of the rape straw pyrolysis gas

The increase of the pyrolysis temperature in the limits between $300^{\circ} \mathrm{C}$ and $800^{\circ} \mathrm{C}$ led to a decrease of the gas density value (Figure 3). High temperatures caused modification of the density, this varying from $1.1\left(300^{\circ} \mathrm{C}\right)$ to $1.7\left(800^{\circ} \mathrm{C}\right)$ but keeping good value for an energy valuable gas [27].

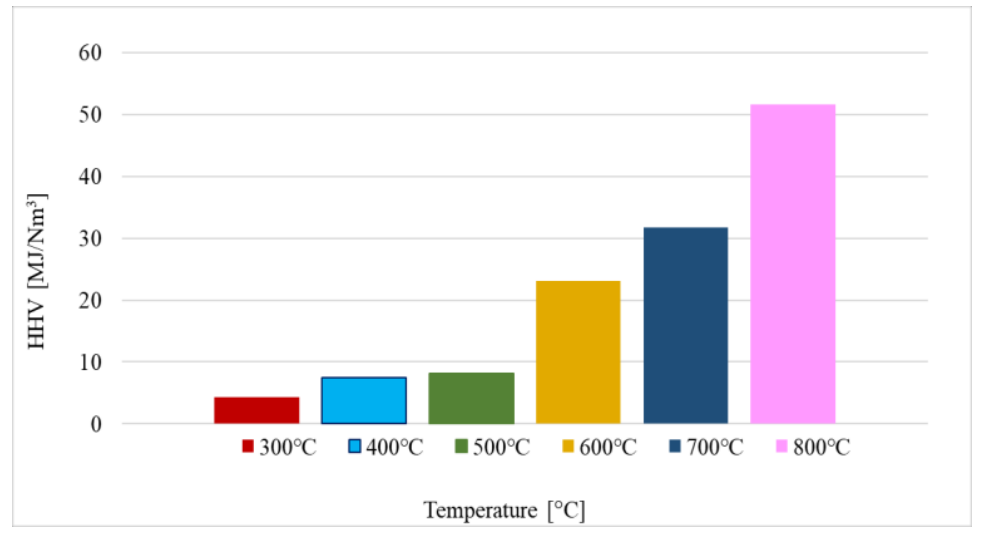

Fig. 4. HHV of rape straw pyrolysis gas

The results of the analysis concerning the energy value of the gas obtained from the pyrolysis processes of the rape straw and developed at low or high temperature showed that HHV depends on temperature (Figure 4). The HHV of the pyrolysis gas started from 4 $\mathrm{MJ} / \mathrm{Nm}^{3}$ for $300^{\circ} \mathrm{C}$, reached $8 \mathrm{MJ} / \mathrm{Nm}^{3}$ at $500^{\circ} \mathrm{C}$ and then increased until to $52 \mathrm{MJ} / \mathrm{Nm}^{3}$ in case of $800^{\circ} \mathrm{C}$. The constant increasing of the gas $\mathrm{HHV}$ while process temperature rises was, also, a result of many pyrolysis experiments developed for biomass [23, 28, 29]. Unlike these studies, in our analysis concerning the pyrolytic gas, the low carbon number hydrocarbons such as $\mathrm{CH}_{4}$ and $\mathrm{C}_{\mathrm{n}} \mathrm{H}_{\mathrm{m}}$ were not considered.

The graphical presentation of the HHV variation for the gas phase demonstrates that high temperature pyrolysis lead to high energy content of the gas, offering the possibility to use this pyrolysis compound as a valuable fuel. For example, recent research demonstrated the ability of homogeneous charge compression ignition (HCCI) engines to run a wide range of fuels, especially when the gas come from pyrolysis and gasification processes [30]. 


\section{Conclusions}

The experimental research study, performed for rape straw pyrolysis and presented along with the two parts of the paper, aimed to establish the effect of the process temperature on the gas products. The first part of the paper was dedicated to establishing the function and the influence of the low temperature conditions on the pyrolysis gas, while the second one to the high temperature pyrolysis. The results of the experiments revealed that the amount of each gas species $\left(\mathrm{CO}_{2}, \mathrm{CO}, \mathrm{H}_{2}\right)$ largely depends on the temperature level in the range of $300^{\circ} \mathrm{C}$ to $700^{\circ} \mathrm{C}$. All the gas compounds were quantitatively characterized, this allowing to identify values for the energy properties of the pyrolysis gas: density and HHV. The results of the rape straw residues pyrolytic conversion demonstrated that high temperatures determine an important increase of $\mathrm{H}_{2}$ content in the gas phase, this strongly affecting the energy potential of the pyrolysis gas. Controlling the process parameters, besides generation of solid and liquid products, pyrolysis provides a flexible and attractive way to convert solid biomass into valuable bio-gaseous fuel, allowing to improve energy efficiency and workability of the biomass usage.

Funding provided through Romania's "Competitiveness Operational Programme 2014-2020" Priority Axis 1: Research, Technological Development and Innovation (RD\&I) to Support Economic Competitiveness and Business Development Action 1.1.4. Attracting high-level personnel from abroad in order to enhance the RD capacity ID/Cod My SMIS: P_37_768/103651; No. Contract: 39/02.09.2016.

\section{References}

1. https://www.ipcc.ch/pdf/assessment-report/ar5/wg3/ipcc_wg3_ar5_frontmatter.pdf (accessed February 2019)

2. S. Jenniches, Renew. Sust. Energ. Rev., 93 (2018)

3. C. Bulmau, G. Ionescu, C. Marculescu Bio-gaseous fuels from agricultural waste pyrolysis (Part I), 9th International Conference on Manufacturing Science and Education MSE 2019 (to be published)

4. E. C. Rada, L. Cioca. Enrgy. Proced., 119 (2017)

5. E. Lakatos, L.I. Cioca, V. Dan, A. Ciomos, O. Crisan, G. Barsan, Sustainability, 10, 3 (2018)

6. EEA, Renewable energy in Europe - 2018. Recent growth and knock-on effects (European Environmental Agency, Luxembourg, 2018)

7. V. Strezov, M. Patterson, V. Zymla., K. Fisher, T.J. Evans, P.F. Nelson, J. Anal. Appl. Pyrol., 79 (2007)

8. J. Lehmann, Bio-energy in the black. Front. Ecol. Environ., 5, 7 (2007)

9. F. Patuzzi, S. Ciuta, M. J. Castaldi, M. Baratieri. J. Anal. Appl. Pyrol., 113 (2015)

10. M. Jahirul, M. Rasul, A. Chowdhury, N. Ashwath, Energies, 5, 12 (2012)

11. S. P. Sohi, E. Krull, E. Lopez-Capel, R. Bol, Adv. Agron., 105 (2010)

12. N. A. Qambrani, M. M. Rahman, S. Won, S. Shim, C. Ra, Renew. Sust. Energ. Rev., 79 (2017)

13. C. Bulmau, I. Stanciulescu, V. Capota, Proceedings of the 17th IEEE International Conference on Environment and Electrical Engineering (IEEE EEEIC) / 1st IEEE Industrial and Commercial Power Systems Europe (2017)

14. M. J. Antal, M. Grønli. Ind. Eng. Chem. Res., 42, 8 (2003)

15. G. Maschio, C. Koufopanos, A. Lucchesi. Bioresource Technol., 42, 3 (1992)

16. F. Verheijen, S. Jeffery, A. C. Bastos, M. Van der Velde, I. Diafas, Biochar Application to Soils - A Critical Scientific Review of Effects on Soil Properties, Processes and Functions (Office for the Official Publications of the European Communities, 2010)

17. B. Biswas, N. Pandey, Y. Bisht, R. Singh, J. Kumar, T. Bhaskar, Bioresource Technol., 237 (2017)

18. C. Gheorghe, C. Mărculescu, A. Badea, C. Dincă, T. Apostol, Proceedings of the 3rd WSEAS Int. Conf. on Renewable Energy Sources (2009) 
19. M Ragazzi, E.C. Rada, Chemosphere, 89, 6 (2012)

20. S.K. Ghosh, Procedia Environ. Sci., 31 (2016)

21. G. Ionescu, C. Bulmău, E3S Web of Conferences, 85 (2019)

22. K. Anastasakis, I. Kitsiou, W. de Jong, Fuel Process. Technol., 142 (2016)

23. Roegiers., J. Pieters, F. Ronsse. Heat and mass transfer modelling of auger reactors (Ghent University, Ghent. 2016)

24. V. Piemonte, M. Capocelli, G. Orticello, L. Di Paola, in Membrane Technologies for Biorefining (2016)

25. J.M. Commandré, H. Lahmidi, S. Salvador, N. Dupassieux, Fuel Process. Technol. 92, 5 (2011)

26. M.G. Rasul, M.I. Jahirul, Proceedings of the $7^{\text {th }}$ WSEAS International Conference on Energy \& Environment (2012)

27. A. Hlavsová, A. Corsaro, H. Raclavská, D. Juchelková, H.Škrobánková, J. \& Frydrych, The Scientific World Journal, 2014 (2014)

28. K. Ronewicz, J. Kluska, Ł. Heda \& D. Kardaś, Drvna Industrija 68, 1 (2017)

29. Y. Xin, H. Cao, Q. Yuan, D. Wang. Waste Manage., 68 (2017).

30. S. Visakhamoorthy, J.Z. Wen, S. Sivoththaman, C.R. Koch, Appl. Energ. 94, C (2012) 